\title{
Improved Cooperation between Schools and Science Labs by Adapting Experiments to the Curriculum
}

\author{
doi:10.3991/ijoe.v7i2.1645 \\ René Sallier $^{1}$, Katja Beckhäuser ${ }^{1,2}$, Benjamin Brück3 and Andreas Schütze ${ }^{1}$ \\ ${ }^{1}$ Saarland University, Saarbruecken, Germany \\ ${ }^{2}$ Warndt-Gymnasium, Voelklingen, Germany \\ ${ }^{3}$ Max-Planck-Gymnasium, Saarlouis, Germany
}

\begin{abstract}
Science labs have repeatedly shown their impact on high school students for increasing the interest in natural sciences and engineering [1]. Due to the fact that pupils are experimenting independently, their natural interest in research can be re-activated due to improved intrinsic motivation. However, with the increasing density in school curricula - in Germany especially caused by the reduction of the high school duration by one year - many teachers do not find the time to visit science labs due to their often extracurricular topics. For our lab SinnTec, which is focused on sensors as the "technical senses", and the experimentation platform VenDASys we are currently adapting existing experiments and examples for improved compatibility with the regular school curricula primarily in Physics. The goal is to integrate the science lab as much as possible into the standard curriculum to reach most pupils.
\end{abstract}

Index Terms—science lab, cooperation, school curricula.

\section{INTRODUCTION AND MOTIVATION}

In the last years the gap between the need and the availability of qualified personnel has been increasing in many technical and scientific fields. One direct consequence is the current drastic shortage of engineers. This problematic situation has been addressed in many activities around the world in didactics and education in different ways, e.g. [2].

Our science lab SinnTec (Sinn für Technik Technische Sinnesorgane) [3] aims at providing hands-on experience for both high school students and teachers. Primarily, students should actively work with microsensors as technical senses to gain a deeper understanding of modern science. In addition, we developed the modular experimentation platform VenDASys [4], which is based on an open source approach for use in schools and projects as well as in our science lab [5]. The VenDASys platform offers a straightforward approach for dealing with sensors by simply "bypassing" most of the electronics from a didactical point of view. Thus students and teachers gain access to modern science and technology in a simple way by using predefined experiments and realizing their own ideas.

\section{COOPERATION WITH AND BETWEEN SCHOOLS}

With this multiple approach combining the experimentation platform VenDASys and the science lab SinnTec, we can offer teachers and students qualified support on several levels:

- Experiments in the science lab directly connected to the curriculum in Physics or other subjects. One example is the blood-pressure monitoring experiment (Fig. 1), which can be connected to Physics lessons either on pressure in the $8^{\text {th }}$ grade or on potentiometer applications in the $9^{\text {th }}$ grade. In addition, this experiment could also be applicable to Biology when dealing with blood circulation.

- Experiments developed for use in the class room, i.e. to illustrate topics from the general Physics curriculum in specific experiments. One example recently developed is a simple experiment for measuring the oscillation period of a pendulum using retro-reflective sensors. Experiments developed by one school can be copied by others by providing all necessary information via our website.

- Development of experiments/demonstrators for e.g. team projects or student competitions. This, however, is purely extra-curricular and should expand the normal spectrum.

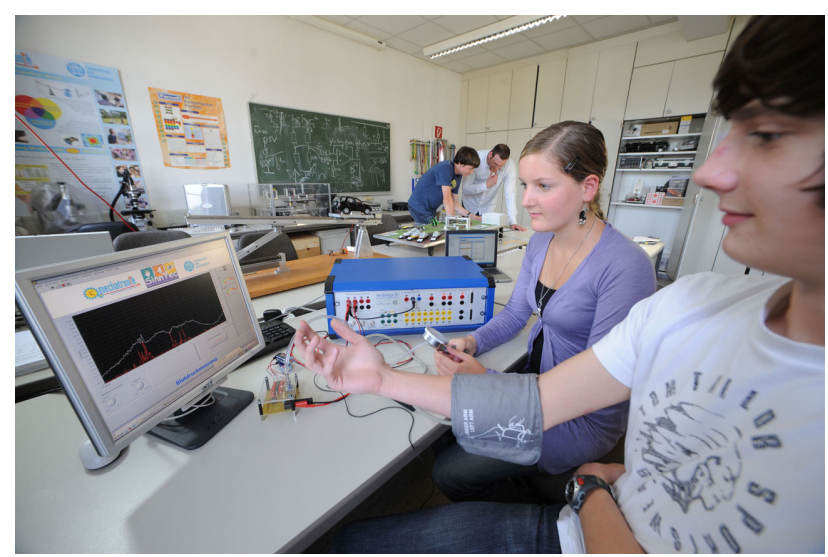

Figure 1. Experiment blood pressure measurement in the lab SinnTec 


\section{A. Improved information for teachers}

To make full use of this concept and to inform teachers of the potential offered especially with regard to the mandatory curriculum, we plan to integrate information about specific experiments, offered either in the school or in our science lab, in the online version of the relevant curricula [6].

\section{HIGH SCHOOL CURRICULA IN GERMANY}

In Germany, Physics is taught in high schools (Gymnasium) leading to the Abitur which allows access to any subject at any university starting in the $7^{\text {th }}$ grade. The curriculum basically consists of an inter-year part which is covering several grades and a grade specific part. In its final form, the curriculum integrates all grades, subjects and levels.

The inter-year part defines the fundamental missions and goals of each subject at the Gymnasium. Thus, this part defines the basis for the education of all subjects. Starting from this basis, in a second step the share or portion of each individual subject is defined for reaching the overriding goals. This structure defines, what the central knowledge and capabilities of the respective subjects are, that are expected from the pupils after successfully completing the respective subjects. Additionally, the inter-year part also gives an overview over the distribution of the covered topics over the different school grades.

The presentation in the grade specific part of the curriculum then lists the content of the respective subject to be covered in a table with two columns (Fig. 2):

- The left column lists all required or mandatory topics of the specific subject. This is relevant because the final exams are centralized so a common basis has to be defined for all schools.

- The right column lists additional topics and suggests possible extensions to the standard mandatory curriculum and basically has the character of a recommendation.

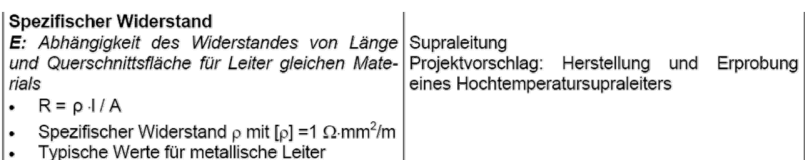

Figure 2. Excerpt from the high school physics curriculum for the $9^{\text {th }}$ grade (topic: specific resistance of an electric conductor).

\section{A. Integration of science lab experiments in the curriculum}

The latest version of the relevant curricula is always available for teachers via the homepage of the Ministry for Education, the so called "education server" [6]. Thus, every teacher can directly access the mandatory and recommended topics for each grade and subject online. As our science lab experiments directly address topics which are contained in the curriculum, a direct link from the respective part of the online curriculum is not only possible but highly desirable to make teachers aware of the offers of not only our but also other science labs. Of course, this can only be done for recommended topics otherwise a visit to the science lab would be mandatory, which would by far exceed the capacity of most labs. Thus, teachers could easily plan the integration of extracurricular offers to fit into their individual course concept as shown in Fig. 3.

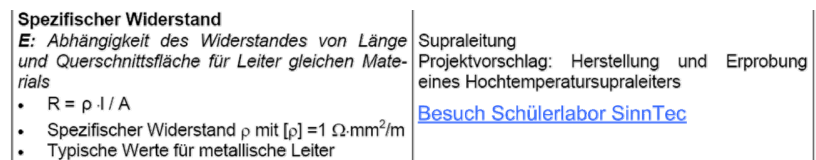

Figure 3. Excerpt from the high school curriculum for the $9^{\text {th }}$ grade showing an exemplary link to the science lab SinnTec. In the science lab, the students would develop an electronic thermometer based on a Pt-100 resistor which they could take home with them, e.g. for further experiments in school.

\section{LINKING SCIENCE LAB EXPERIMENTS WITH THE \\ High SCHOOL CURRICULUM: THE EXPERIMENT ON BLOOD PRESSURE MONITORING}

To elucidate the idea and the usefulness of linking science lab experiments directly with the curriculum, the experiment on blood pressure monitoring will be given as an example showing its thematic adaptation to different curricular topics in different grades. In general, the experiments in the student laboratory SinnTec are designed to be an active learning experience usually divided into three general stages: introduction to the measurement basics, i.e. the physical principles behind the sensor and the application derived from everyday applications, introduction to the required electronics and, finally, experiments with the sensors (Fig. 4).

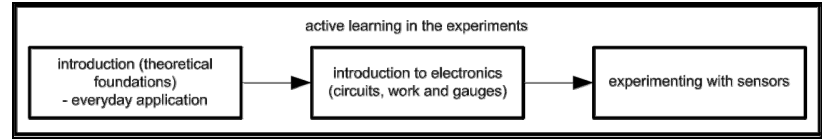

Figure 4. Flow chart of experiments and/or stations in the student laboratory SinnTec.

In the experiment blood pressure monitoring, the students should learn to recognize and understand the different parts of a technical system which they already know from their everyday experience. By taking a practical example students should overcome their respect and sometimes fear of the necessary electronics which are used in the system. The concept of the experiment blood pressure monitoring is based on four separate stations as shown in Fig. 5. This experiment is realized as an "experimentation circle". The advantage of working with separate stations is the possibility to concentrate on different topics of the overall experiment and thus break down the complexity to manageable proportions. The students become acquainted with the experiment as a whole in individual steps to avoid overtaxing them with an experiment covering a wide range of topics. In addition, the separate stations allow an adaption of the individual experimental stations suitable for the respective grade of the students. Thus, teachers can actually visit the lab several times for the same experiment and/or draw on the results and experience gained in the science lab in their regular classes. This considerably increases the learning experience of the experiment for the students. 
PAPER

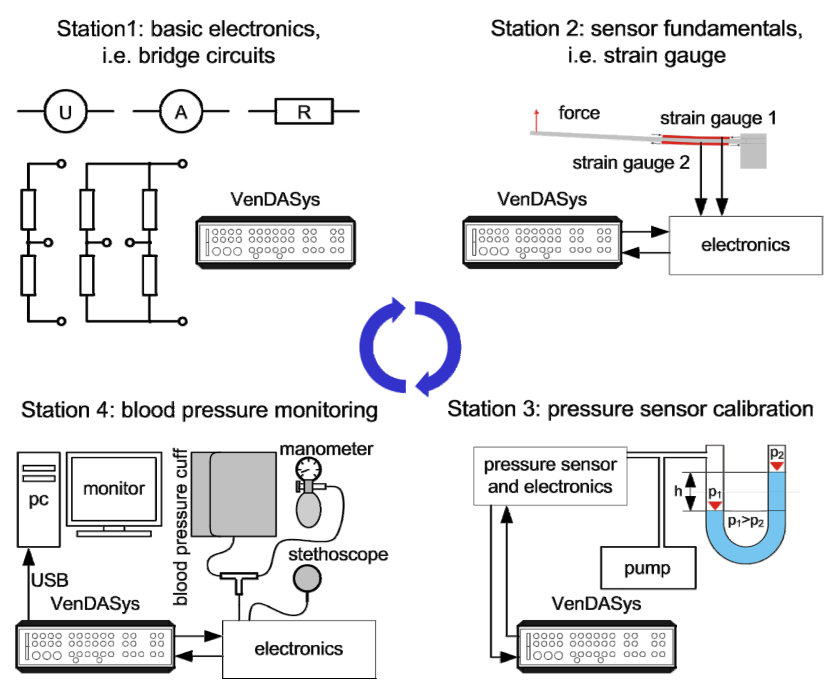

Figure 5. Experimental stations of the experiment on blood pressure monitoring. The stations are independent of each other and address different aspects of blood pressure monitoring and the required sensor technology.

\section{A. Station 1 - basic electronics}

At this station the students first perform simple measurements of voltage and resistance to become acquainted with using basic digital multimeters. In this context the students also repeat and enhance basic knowledge learned in their regular school lessons concerning the basic electrical values voltage, current and resistance in simple electrical circuits. In addition, the students measure different resistances using a potentiometer and using different combinations of resistances. Finally a simple Wheatstone bridge circuit is introduced as a fundamental tool for measuring small resistance changes as is necessary for measuring the resistance change of a strain gauge (Fig. 6).

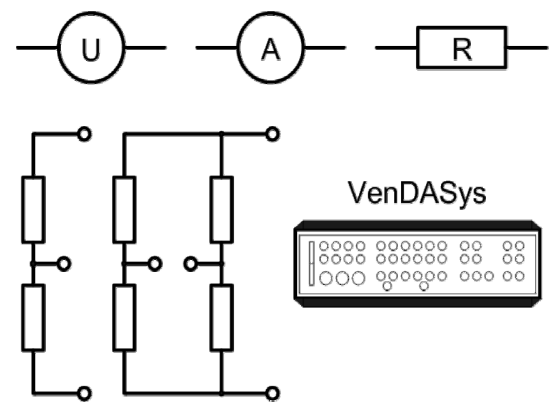

Figure 6. Station 1 - basic electronics introducing a bridge circuit for measuring small resistance changes.

The experiments performed at this station are connected thematically to the Physics curriculum of the $9^{\text {th }}$ grade covering series and parallel connections of resistors and can be linked in the appropriate sections of the online curriculum (Fig. 7).

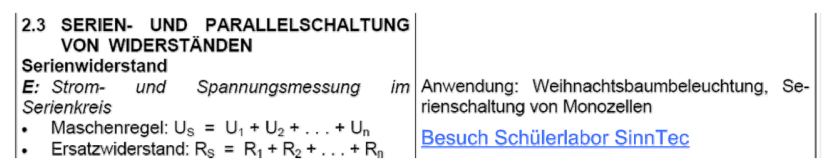

Figure 7. Possible integration of station 1 in the online curriculum in the section covering parallel and series connections of resistors.

\section{B. Station 2 - sensor fundamentals}

At this station the students are introduced to the strain gauge, i.e. a variable resistor changing its resistance due to mechanical strain. At first, the basic function principle of the strain gauge, i.e. the resistance change caused by the elongation of a metal wire due to mechanical strain, is explained. Then, students experiment individually and autonomously with strain gauges using a simple bending beam set-up as shown in Fig. 8.

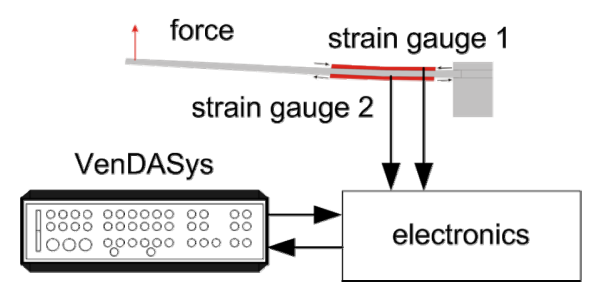

Figure 8. Station 2 - sensor fundamentals. Students experiment with strain gauges using a simple bending beam set-up and bridge circuit.

In this set-up, two strain gauges are glued to the upper and lower side of a metal beam which is bent by placing small weights on the beam. The students experiment with different weights and positions of the weights to understand that the resistance change is proportional to the beam bending. For measuring the resistance change a bridge circuit as developed in station 1 is used. The bridge output voltage is amplified with a suitable electronic circuit and visualized with either a normal multimeter or using the experimentation platform VenDASys, which also allows recording the measured values vs. time.

Finally the students learn the basic construction of a typical pressure sensor which is based on strain gauges mounted on a thin membrane. For this, a macro model of a typical silicon pressure sensor, shown in Fig. 9, was realized, Fig. 10.

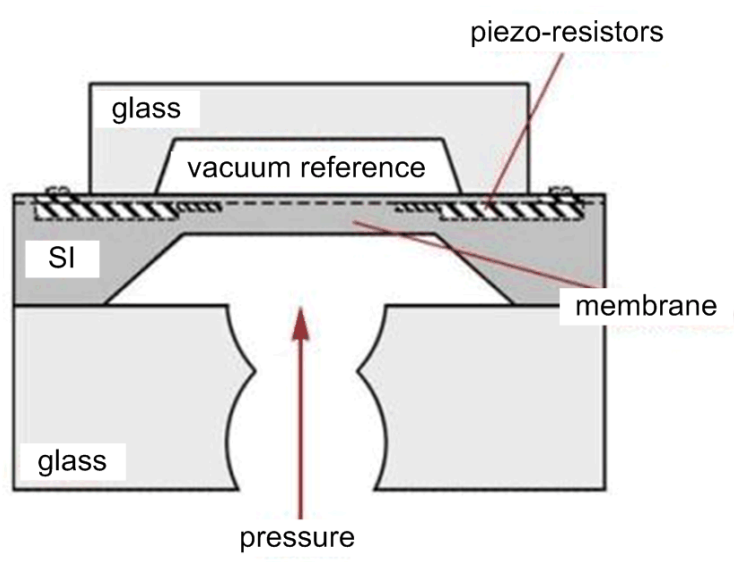

Figure 9. Schematic of a piezo-resistive absolute pressure sensor realized using Silicon micromachining (adapted after [7]).

The experiments performed at this station are connected thematically to the Physics curriculum of the $9^{\text {th }}$ grade covering the dependence of real resistors from the specific resistance and its geometry and can be linked in the appropriate sections of the online curriculum (Fig. 3). 
PAPER

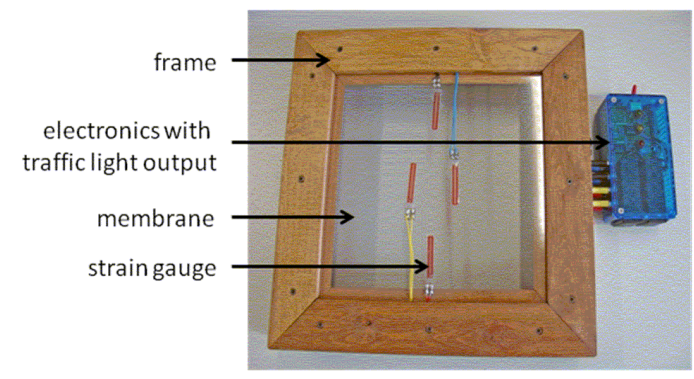

Figure 10. Macro model of a pressure sensor (size approx. $30 \mathrm{~cm}$ square). Applying pressure to the membrane results in a simple traffic light output (green: low, yellow medium and red high pressure, respectively).

\section{Station 3-calibration of the pressure sensor}

At this station students are shown that every sensor needs to be calibrated before exact measurements can be performed. In our experiment we use the pressure of a water column caused by the weight of the water above the sensor membrane, Fig. 11, left. The resulting electric signal of a standard pressure sensor - containing a bridge circuit consisting of four strain gauges - is measured with an electronic amplifier circuit (Fig. 10, right) and a multimeter or again using the VenDASys as in station 2 .

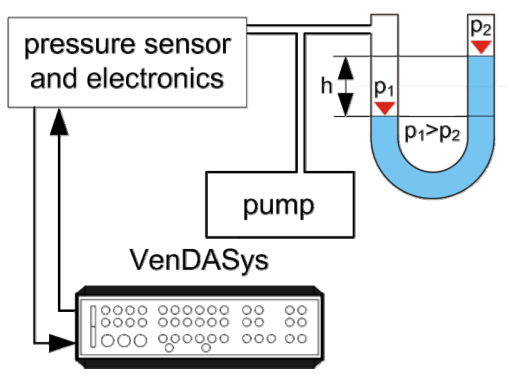

Figure 11. Station 3 - calibration of a standard micromachined pressure sensor using a water column (left) and an amplifier circuit (right).

The experiments performed at this station are connected thematically to the Physics curriculum of the $8^{\text {th }}$ grade covering the pressure caused by the weight of liquids in a $\mathrm{U}$ tube as in our water column (Fig. 12). The recommended topics for this subject also mention pressure sensors and the importance of pressure for living beings.

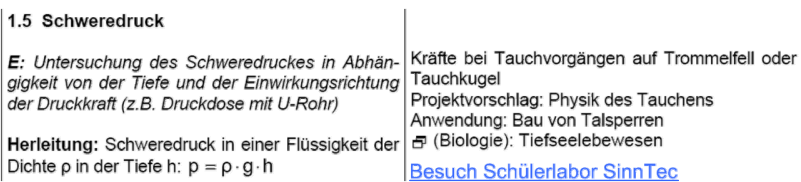

Figure 12. Possible integration of the topic pressure and pressure generation with a water column in the curriculum for $8^{\text {th }}$ grade.

\section{Station 4-blood pressure monitoring}

At this station all the different components covered before are linked to allow the monitoring of the blood pressure. The students can apply their knowledge gained in the previous stations in this inter-subject experiment connecting Physics and electronics with Biology. The blood pressure monitoring is based on the principle of Riva-Rocci [5]. At first, the blood pressure is measured manually in the same way as, e.g., a general practitioner would. This is used to show the students the advantage of an objective automatic measurement approach for minimizing or avoiding errors, e.g. caused by reading of a scale in a brief instant. Then, the measurement is repeated with the pressure sensor calibrated in station 3 using the circuits developed in stations 1 and 2 as shown in Fig. 13. The measurement results, i.e. the blood pressure curve and the Korotkoff sounds recorded by a microphone, are visualized using the experimentation platform VenDASys, Fig. 14. Fig. 1 shows students during this final stage of the experiment.

The overall experiment at this station can be linked in the online curriculum to the appropriate sections in Physics but also in Biology. The duration of the complete experiment, i.e. covering all four stations, is approx. four hours. Up to 16 students, four at each station, can take part in the experiment.

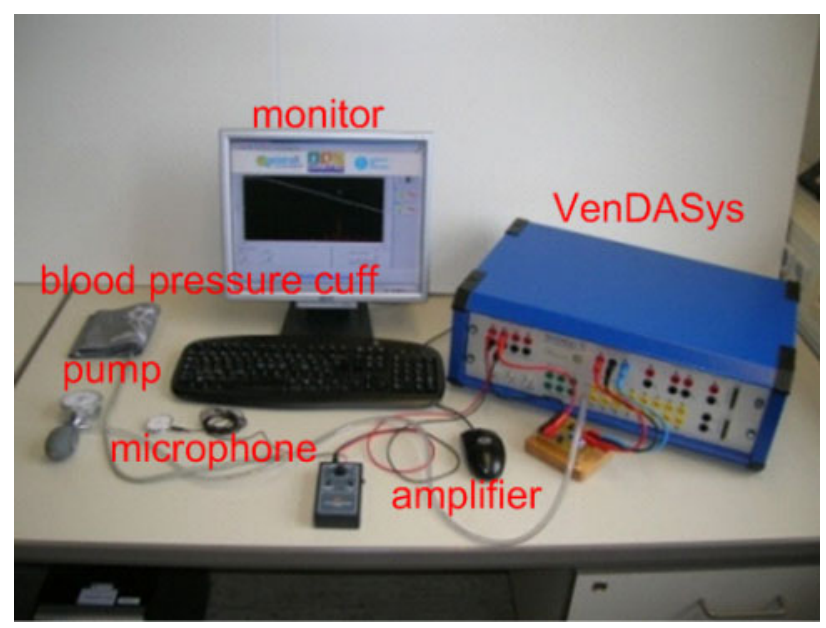

Figure 13. Complete experimental set-up for blood pressure monitoring

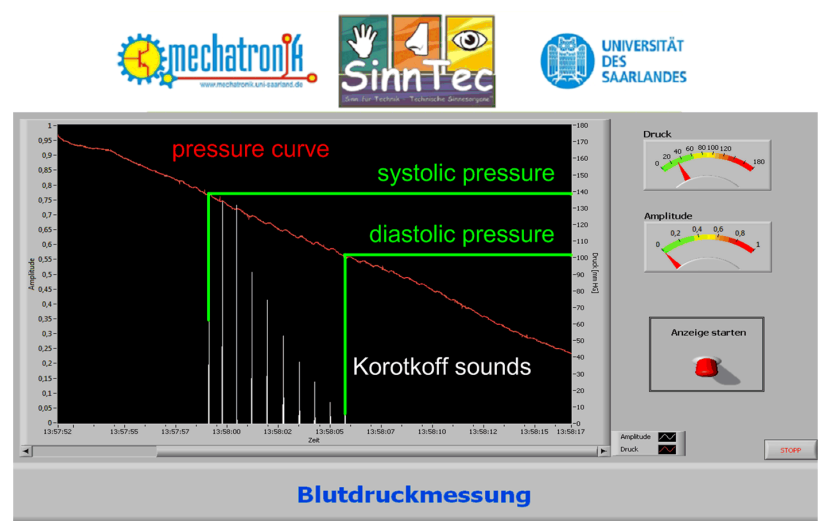

Figure 14. Result of a blood pressure monitoring experiment visualized using the experimentation platform VenDASys (LabVIEW front panel). The graph shows the measured pressure curve (red) and the so called Korotkoff sounds caused by the blood pulsing in the veins. The onset of the Korotkoff sounds denotes the systolic, the end the diastolic blood pressure.

\section{EXAMPLE FOR AN EXPERIMENT DEVELOPED IN A PARTNER SCHOOL USING THE VENDASYS PLATFORM}

In this section we outline an experiment developed by students and teachers in their school (Max-PlanckGymnasium Saarloius) for use in regular school lessons 
but also in extracurricular activities [8]. The experiment covers the measurement of the oscillation period of a pendulum using a retro-reflective light sensor or a photo transistor and the VenDASys platform. Simple experiments such as the one described here have the advantage of involving the students themselves in the development and set-up of the experiment. The students first have to understand the theory behind the experiment and then have to transfer this to the real experiment. Thus the pure theoretical knowledge is transformed into profound understanding of the experimental conditions. This realization leads to a better long term comprehension than the theoretical presentation alone.

In addition, the students fully identify themselves with the problem at hand and often show a greater motivation compared to regular direct instruction by the teacher without their direct involvement. When using experiments developed by or at least together with students in regular lessons, these students become role models for others encouraging them, e.g., to also work in school projects. Ideally, the structure of the class as a whole will profit by encouraging more students to actively participate in various topics and by showing the students that they can contribute to the lessons in a meaningful way.

\section{A. The retro-reflective sensor}

At the beginning of the experiment the students are familiarized with the basics and a possible realization of a retro-reflective light sensor, which can be used for measuring, e.g. the passing of a pendulum. In a retroreflective sensor a light beam, e.g. from an LED or a classroom laser, falls on a phototransistor which will then change from insulating state to conducting state. This transistor is connected in series with a resistor and a power supply as shown in Fig. 15. In the conduction state a voltage drop is recorded across the resistor due to the current flowing through the circuit, while in the insulating state (no light on the phototransistor) the current and thus the voltage across the resistor are Zero. Thus, the signal of the circuit changes from high to low voltage when the light beam is interrupted, i.e. by a pendulum swinging through the gap between light source and phototransistor.

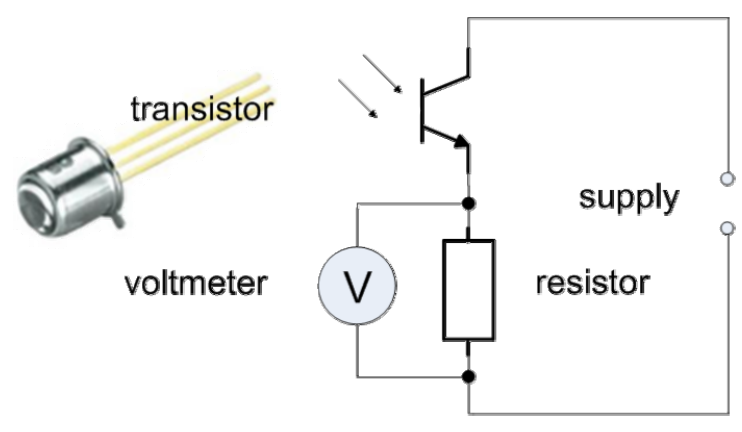

Figure 15. Simple circuit for measuring light with a phototransistor and a resistor connected in series.

\section{B. Measuring time periods using VenDASys}

In the second step of the experiment the students are introduced briefly to the experimentation platform VenDASys. In this experiment, VenDASys is used to measure the voltage across the resistor vs. time and to visualize the resulting data. The students can first manually interrupt the light beam of the retro-reflective sensor and then combine the set-up with a pendulum to measure its oscillation period. The students learn to interpret the obtained data graphs and evaluate these to determine exact time intervals or periods.

\section{Experiments with a pendulum}

In the experiments with the pendulum, shown in Fig. 16, students should learn to observe the experimental dependencies of the pendulum oscillation period from the experimental set-up by varying the set-up in a systematic way and to deduct a theoretical model or description from these experiments. At first, students are asked to guess which experimental conditions have an influence on the pendulum oscillation period. The experiments are then used to verify or disprove their assumptions. The students should discover:

- The oscillation period primarily depends on the length of the pendulum. If the length is quadrupled, the oscillation period doubles.

- The oscillation period is independent of the weight of the pendulum.

- The amplitude of the oscillation has a small influence on the period if the chosen amplitude is very large.

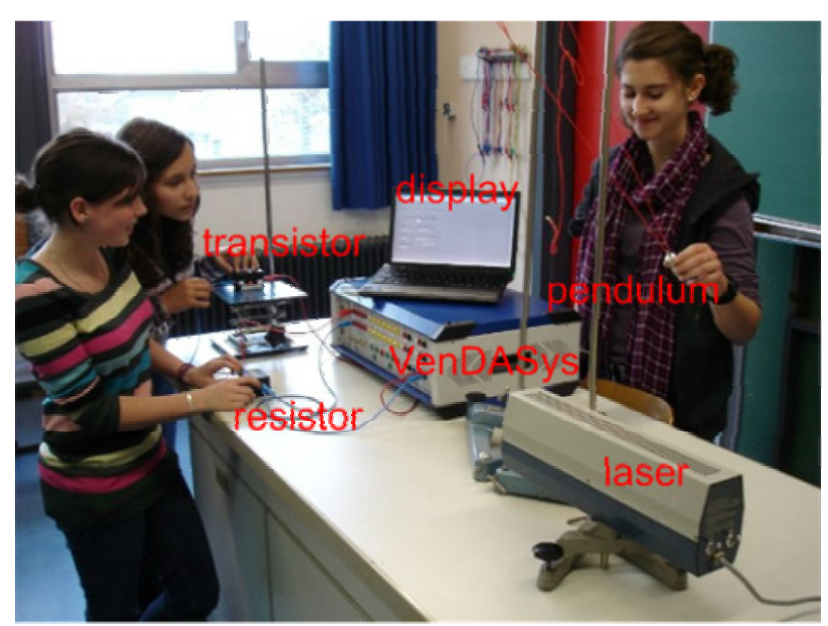

Figure 16. Experimental set-up for measuring the oscillation period of a pendulum with a laser beam and phototransistor.

This example shows that simple experiments can be integrated in extracurricular activities, i.e. in group projects, or directly in the school lessons, at least if sufficient experimental equipment is available to allow students to work in small groups. We tested this approach in the frame of a "Technology congress for girls" [8]. The participants, nearly 200 girls from grade 9 to 12 from several different schools in the German federal states Saarland and Rhineland-Palatinate, could choose in advance which of nearly 20 workshops offered in different topics they wanted to participate in. Only very few chose the offered workshop "Experimenting with the VenDASys", mainly because the topic electronics and physics did not seem attractive to the young girls. The evaluation after the congress, however, showed that this workshop had actually received the second highest approval by the participants of all workshops. This proves that even these "hard" topics can actually reach and fascinate young students and also girls, if it is presented in 
an experimental context instead of a normal direct presentation.

\section{Self-Study COURSES AND TEACHER-Training FOR USING THE VENDASYS PLATFORM IN SCHOOLS}

Teachers can insert the VenDASys platform in their regular class work for experiments, as described in the previous chapter. To make use of this possibility, i.e. develop experiments themselves or have experiments developed jointly by students, they must be trained accordingly in the use and the concept of this platform. For this purpose specific self-study courses for the students and a "train the trainer" course for teachers were developed according to the "guiding text" method and realized with a partner school (Max-Planck-Gymnasium Saarlouis). The overall concept of VenDASys platform is shown in Fig. 17 [5]

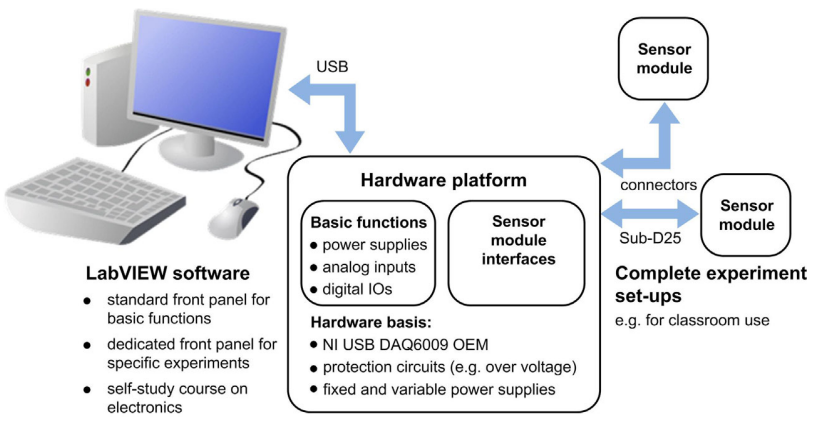

Figure 17. VenDASys system overview

In the first step, teachers and students need to learn how they can use the software LabVIEW (Laboratory Virtual Instrumentation Engineering Workbench, National Instruments) to control the functions of the VenDASys platform. For this purpose a specific LabVIEW selftraining course was developed [4]. In this course, the teachers and students are individually introduced to the first necessary steps and functions as well as the building blocks of this graphical software, the so-called VIs (Virtual Instruments), and can gain experience in dealing with them independently. The self-study courses were realized using Flash videos embedded in HTML script to allow an individual learning speed and a simple use of the courses based on any standard web browser. The user can jump forwards and backwards at any time to skip or repeat specific passages (Fig. 18).

After becoming familiar with the LabVIEW software and its use, teachers and students are then introduced to the VenDASys platform and its functions in a second selfstudy course focusing on electronics [4], (Fig. 19). Furthermore, in this course the VIs developed for controlling the various VenDASys functions are presented and explained (Fig. 20). This course was also embedded as a Flash video into an HTML script, to ensure simple, ubiquitous operation and to allow individual learning tempo.

After completing these two self-study courses, teachers and students should be well prepared to realize their own experiments using the experimentation platform VenDASys.

To introduce teachers to the VenDASys platform and its general concept and to present the accompanying self-

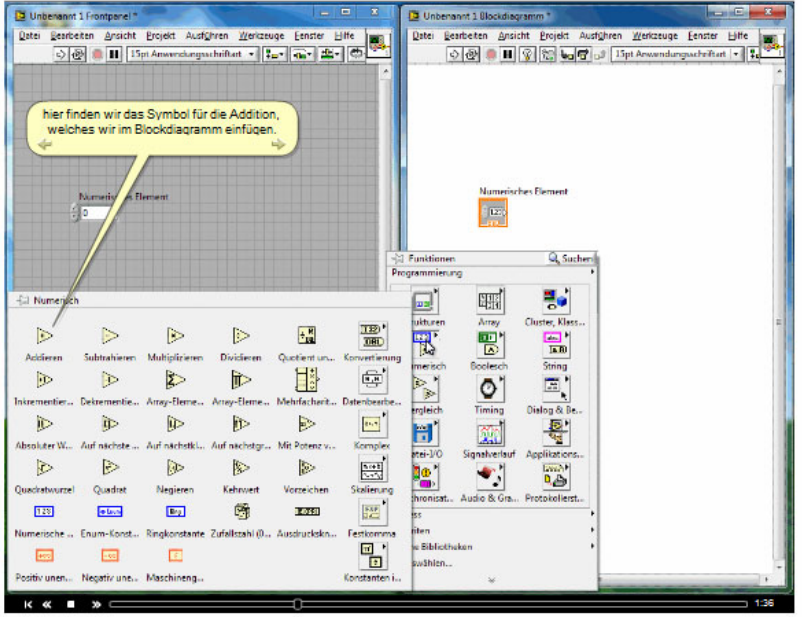

Zur Lösung von Aufgabe $1 \quad \underline{\text { Zurück zu Kapitel } 2} \quad \underline{\text { Weiter zu Kapitel } 4}$

Figure 18. Screenshot of a flash video from the LabVIEW self-study course; here, the realization of the function "addition" is explained.

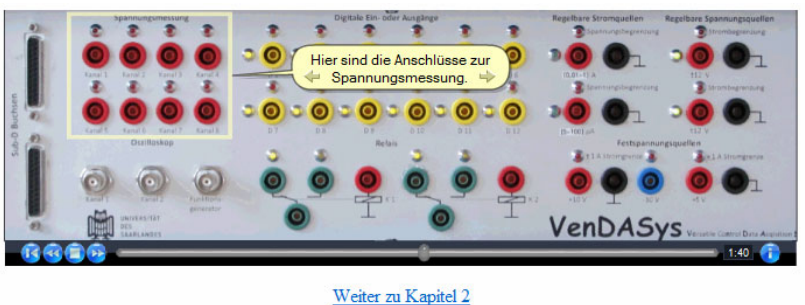

Figure 19. Screenshot of a flash video from the VenDASys self-study course; here, the function of the different front panel connectors is explained, marked are the connectors for voltage measurements.

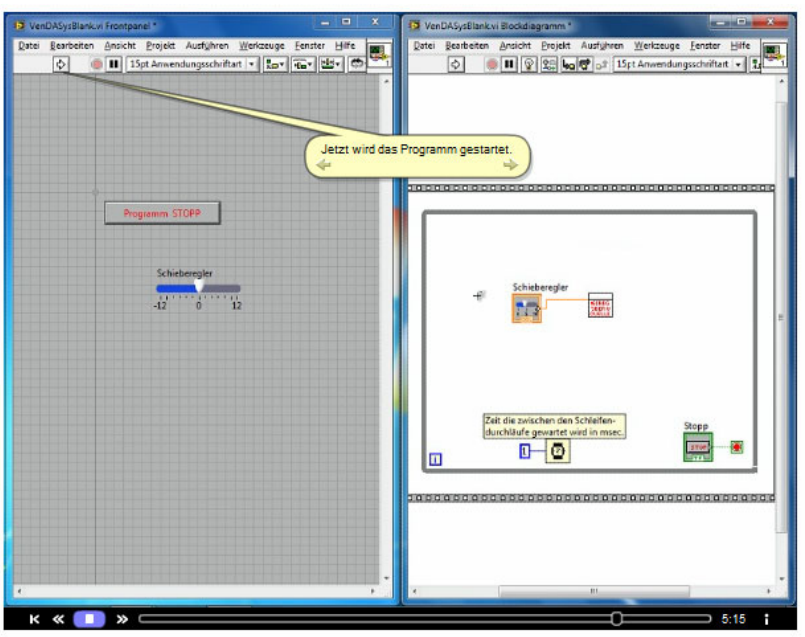

$$
\text { Zurück zu Kapitel } 2 \text { Weiter zu Kapitel } 4
$$

Figure 20. Screenshot of a flash video from the VenDASys self-study course; here, an example is given for a VI which is used to set a control value using a slider.

study courses a teacher training was realized at one partner school (Max-Planck-Gymnasium, Saarlouis). A dedicated room was equipped with eight VenDASys platforms together with some building blocks for simple experiments, e.g. light bulbs, resistors, diodes etc. A typical training day consists of an introduction of the concept of the VenDASys platform which is illustrated 
PAPER

with examples of projects and experiments to generate interest of the participating teachers for this novel educational tool. Afterwards, the participants complete the two self-study courses individually and complete the training by developing and implementing simple experiments using the provided building blocks (Fig. 21).
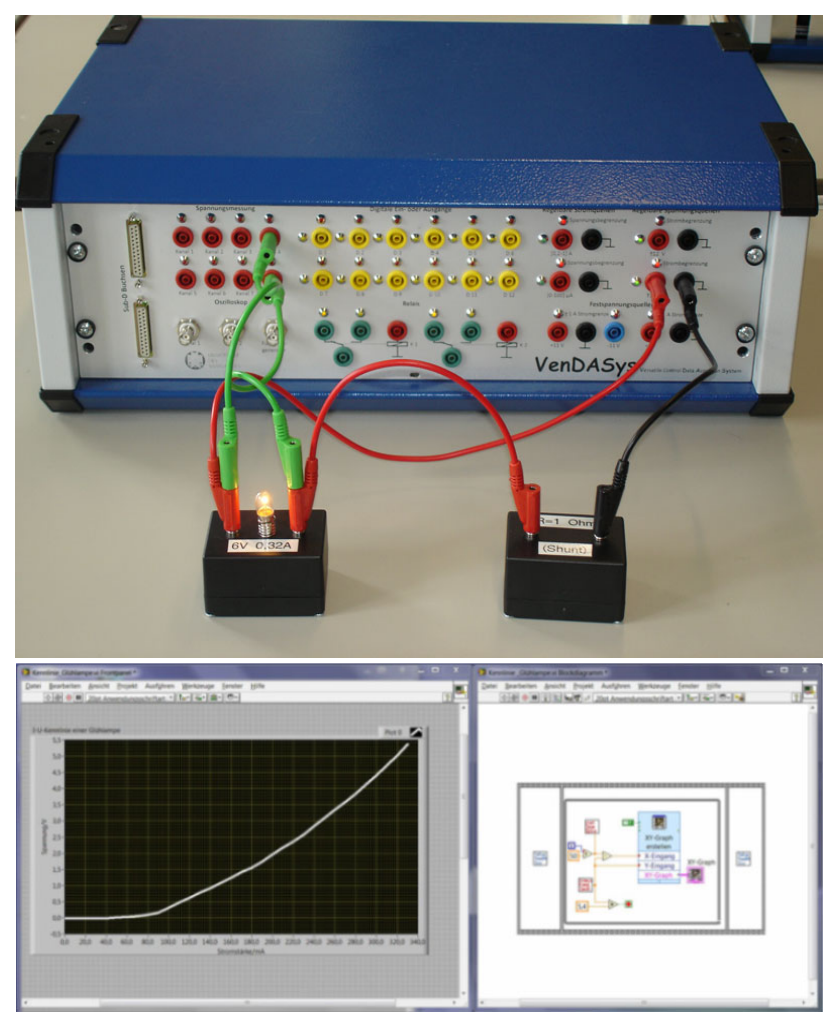

Figure 21. Exemplary realization of a simple experiment during a teacher training using the VenDASys platform: the I-U characteristic of a light bulb is measured and plotted showing the change of resistance caused by heating the filament. Top: experimental setup with a light bulb and series resistor; bottom: resulting characteristic curve (left) measured automatically using a simple LabVIEW-VI (right).

\section{CONCLUSION AND OUTLOOK}

The two exemplary experiments blood pressure monitoring and oscillation period of a pendulum presented in this paper show that there are several possibilities to increase and enhance the cooperation between schools on the one hand and universities, research organizations and even industry on the other hand. The common aim is to increase the motivation especially for math, natural sciences and technical applications and make these subjects more attractive to students in general and girls in particular by offering a more diverse and interesting presentation of mandatory topics.

The universal experimentation platform VenDASys [5] offers the possibility for students and teachers alike to realize their own ideas for experiments due to its versatile. Students and teachers alike can concentrate on the development and realization of their experiments instead of spending a lot of effort on the necessary periphery. Experiments are simplified considerably by transparent integration of various functions necessary for natural science and technical experiments in one system.

In addition, learning is enhanced if the lessons are not only presenting theoretical knowledge, which is often too abstract for a large part of the students. By showing natural science theory in an experimental context connected to technical, everyday applications allows students to convert theoretical knowledge into profound understanding. Knowledge obtained in this way is proven to have a more lasting effect and can be applied efficiently if similar problems are encountered to solve these problems [9, 10].

An additional positive aspect results from the students working together in a team, which is typical for the cooperation in these experiments. The students learn to organize their work together in the team and this team work also conveys important social competences which are of great importance in the modern world.

The planned direct linking of experiments, either offered in science labs (e.g. blood pressure monitoring) or for implementation in the school itself (e.g. oscillation period of a pendulum), in the online curricula will allow teachers to find different possibilities to enhance their lessons and offer their students intellectual stimulation. The reduced effort for finding ideas and integrating them in the lessons will allow teachers to spend more time with their students and help them individually.

Our experience with different groups of students using this approach, either within our science lab SinnTec, within school activities or at special events like a science congress, have been very positive so far. The feedback from students has shown that the described approach, i.e. conveying knowledge via experiments connected to everyday experience, is received very positively by students. With this approach we hope to contribute to finding solutions for addressing the increasing demand in young talents, especially in natural sciences and technology.

The developed self-study courses for LabVIEW and for using the VenDASys platform can be used by sudents and teachers alike. Especially for students, these courses allow an individual and self-controlled learning tempo, i.e. giving slower students more time to understand the basic principles and fundamental requirements while allowing faster students to "play around" and gain further experience by experimenting without getting bored. This is a highly important aspect in achieving the best possible outcome, i.e. learning experience, for each individual student, which is a critical aspect especially in lower grades with a wide spectrum of student capabilities.

It is interesting to note that the self-study courses are often completed faster by students than by teachers, even though the background knowledge of the teachers is much higher. We suspect that this is due to the web-based learning format which is more familiar to today's computer literate students than especially older generation teachers.

By appropriate training offers for teachers, these also gain the opportunity to familiarize themselves with the potential of the VenDASys experimental platform and its capabilities under guidance of experienced experts. In this frame they also gain first practical experience and will have their first personal successes in order to overcome the typical stumbling blocks for making efficient use of this or other novel approaches to teaching. In our experience there is typically a widespread reluctance to introduce new methods and this can only be overcome by showing the teachers how to make efficient use of the 
PAPER

methods. The best way for this is clearly to show examples of successful use in other schools in a similar context. This is a crucial starting point for the multiplier effect of the teachers in the respective schools: without the teachers school labs in particular and novel approaches to engineering education at the high school level in general will not be able to reach the broad majority of students.

\section{ACKNOWLEDGMENT}

We thank Richard Baumbach, Wirtschaftsgymnasium Saarbrücken, for his ideas and support in developing the VenDASys concept and in disseminating it to other schools.

\section{REFERENCES}

[1] G M. Euler: Quality Development: Challenges to Physics Education, in: Proc. Int. School of Physics "Enrico Fermi", Course CLVI, 2003.

[2] Proc. IEEE Conference: Meeting the Growing Demand for Engineers and Their Educators 2010-2020, ISBN: 978-1-42441916-6.

[3] http://www.sinntec.uni-saarland.de

[4] http://www.vendasys.uni-saarland.de

[5] R. Sallier, R. Mißler, A. Schütze: VenDASys - A Versatile Experimentation Platform for Educational Purposes; iJOE 3/10, International Journal of Online Engineering, Vol. 6, Issue 3, August 2010, pp. 43-49.

[6] http://www.saarland.de/lehrplaene.htm

[7] Image online: http://www.kfztech.de/kfztechnik/fahrwerk/reifen/ drucksensor sensoNor.jpg

[8] R. Sallier, B. Brück, C. Hort, A. Schütze: „Experimentieren mit der VenDASys", Mädchen Technik Kongress, Pirmasens, Germany, Workshop 16, September 15, 2010

[9] H. Schmidkunz, H. Lindemann: Das Forschend - Entwickelnde Unterrichtsverfahren, Problemlösungen im naturwissenschaftlichen Unterricht; 6. unveränderte Auflage, Nachdruck der 3. Auflage von 1992; Didaktik,
Naturwissenschaften Band 2; Westarp Wissenschaften Verlagsgesellschaft $\mathrm{mbH}$, Hohenwarsleben 2003; ISBN 978-389432-042-3

[10] R. Messner (Hrsg.): Schule forscht: Ansätze und Methoden zum forschenden Lernen; edition Körber - Stiftung, Hamburg 2009; ISBN 978-389684-335-7

\section{AUTHORS}

R. Sallier studied electrical engineering and received his M.Sc. from the technical university Kaiserslautern in 2007. He is currently a research associate at the Lab for Measurement Technology (LMT) in the Department of Mechatronics, Saarland University, Saarbrücken, Germany (e-mail: r.sallier@lmt.uni-saarland.de). His research emphasis is the development of the VenDASys platform and the evaluation of the effects achieved with this platform in schools and student projects.

K. Beckhäuser is staff member in the student laboratory SinnTec and teaches Physics and Mathematics at the Warndt-Gymnasium, Voelklingen, Germany.

B. Brück teaches Physics and Mathematics at the MaxPlanck-Gymnasium, Saarlouis, Germany.

Prof. Dr. A. Schütze studied physics at the RWTH Aachen and received his Ph.D. in applied physics from JLU Gießen in 1994. Since 2000 he is full professor at Saarland University and head of the Laboratory for Measurement Technology (e-mail: schuetze@1mt.unisaarland.de).

This work is supported in part by the Saarland Ministry of Economics and Science. We would like to thank for the financial support.

This article is an extended version of a paper presented at the IEEE EDUCON20211 Conference, held from April 4th-6th, 2011, in Amman, Jordan. Received: April 24 $4^{\text {th }}$, 2011. Published as resubmitted by the authors May $2^{\text {nd }}, 2011$. 